\title{
1. Introduction to managing the global organization
}

The internationalization of businesses has become a reality all over the world. It is not just the richer countries of the world, such as the US, the UK, Germany, France, Japan, and Italy, that are expanding their international operations to culturally dissimilar countries, but there has also been significant growth of international business activities on the part of corporations from the emerging economies. The 2003 BRIC report (on Brazil, Russia, India, and China) by the global financial firm of Goldman Sachs states that in 2040 the largest economies of the world will be the US, followed by the People's Republic of China (including Hong Kong), and India. The economies of Brazil and Russia are currently behind the economies of China and India.

Such a phenomenon was inconceivable in the early 1960s when Gunnar Myrdal coined the term "the Asian drama" in his classic inquiry into the riches and poverties of nations (1968). Myrdal, a Nobel laureate in economics, inquired into the economic and non-economic factors that are responsible for spurring as well as sustaining economic growth in different regions of the world.

While not explicitly concerned with the concept of cultural differences in fostering or impeding the economic growth of nations, he observed that China, India, and other central Asian countries are probably destined to remain poor nations for an indefinite period, including the early parts of the 21 st century. The leaders of the world respected greatly the analyses provided by Myrdal at that time. However, as we look at the comparative economic statistics of these huge Asian economies, as well as of the countries that did not encourage capitalistic forms of growth, it is remarkable that it is precisely the countries that Myrdal was pessimistic about that are doing so well in the 2010 world economy. They are destined to become the largest importers and exporters and are also providing foreign direct investments to the first nations of the world, including the premier economy of the world. In the US 1.5 trillion dollars of the foreign deficit was financed by China.

There are a number of historical, economic, political, institutional, and cultural factors that are responsible for the very slow growth of the Asian, 
Latin American, and African economies of the world after World War II. While we will briefly discuss the importance of the first four factors, it is our objective in this book, and especially in this chapter, to discuss the role of cultural differences, which is one of the important determinants of economic growth and organizational performance in various economies of the world, regardless of their location. The next section is dedicated to the concept of culture and cultural differences. We adopt an evolutionary perspective in that we like to trace the importance of this phenomenon over the historical development of countries. In other words, the role of cultural differences (and how they influence various economic activities on which the prosperity of the people and the growth of the country depend) is remarkably different in different geographical regions of the world. The nature of relationships between the phenomenon of culture and the economic prosperity of a country will be traced from an evolutionary perspective. It is only then that we can begin to appreciate the complete role of cultural differences and their significance in managing across cultures.

\section{HISTORICAL BACKGROUND OF THE CULTURE CONCEPT}

A team of renowned cross-cultural psychologists (Berry, Poortinga, Segall, \& Dasen, 2006) provide a framework that is very helpful for understanding the evolution of the phenomenon of culture within an eco-cultural framework. We present an adapted version of this framework (Figure 1.1) which shows that culture evolves within the geographical context of a nation as a function of ecological (the nature of the physical environment and climate, the way people make a living in that culture) variables as well as cultural diffusion. Socio-political and economic (history of various political and administrative systems in the country, the nature of wars and other serious conflicts) factors are also very important. The kind of adaptation that humans make to their environment is a product of the interaction between the ecological factors and the influences of historical, economic, social, and political factors.

For example, the physical characteristics of people from sub-Saharan Africa and the Middle East are remarkably different from people of the Nordic countries of Europe and also from Slavic countries in central Asia. Skin pigmentation of the people of Africa is a function of the temperature and sunlight that have affected Africans for centuries. In contrast, the light skin colors and blonde hair of Scandinavian people are a function of long dark winters which provide very little exposure to the sun's rays. The Slavic people from central Asia and people from the Middle East tend not 


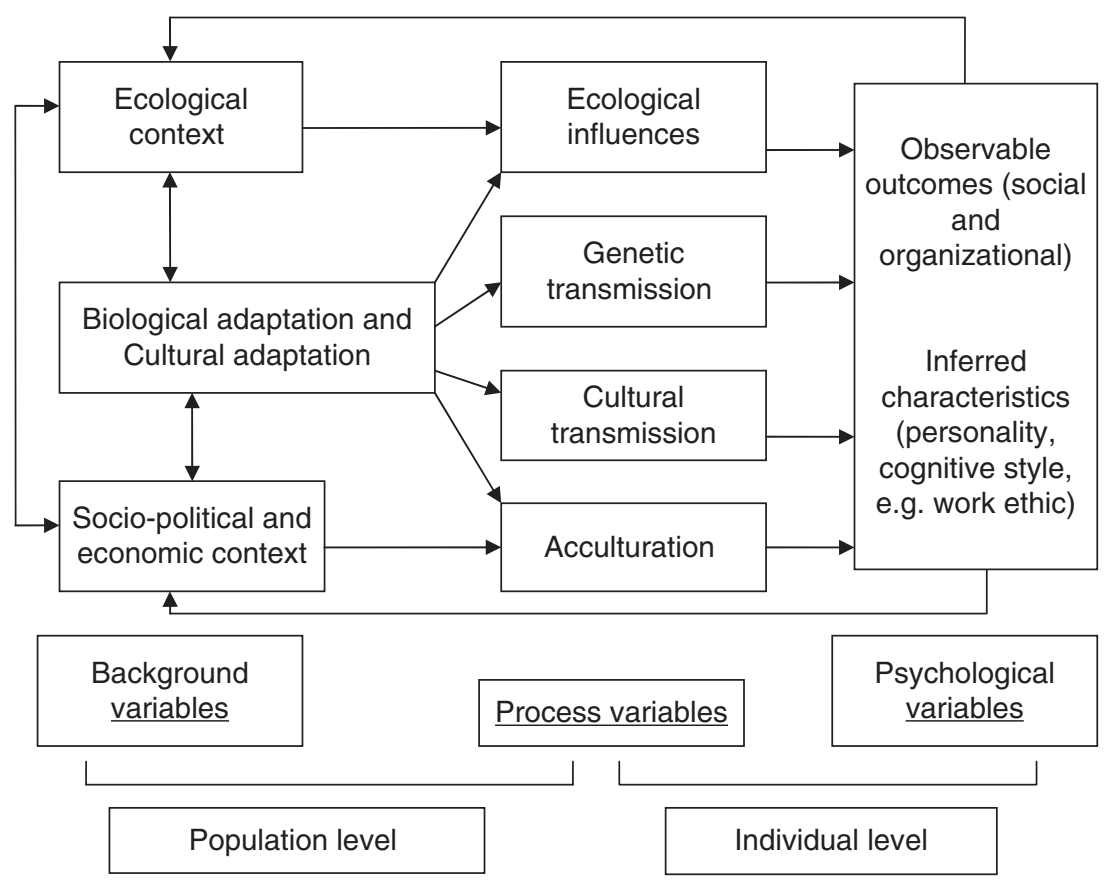

Figure 1.1 An eco-cultural model of cultural transmission

to be as tall as people from Northern Europe as a general rule, but they are somewhat heavier.

In a similar fashion, the cultural values of the societies of Africa, the Middle East, Northern Europe, and modern-day America are quite different from each other. This is largely due to the processes of adaptation of humans in these societies which have been quite different from each other in the past and continue to be different even today. For example, the history of freedom struggles in the North American context which took place around the late 1700s was quite different from the kinds of historical struggles that Slavic people encountered in Czarist Russia of the 1700s. The social behavior of Russians in general is more sensitive to the approval of higher authorities than is the behavior of European Americans. American behavior is in part the consequence of freedom struggles with the British Empire in the late 18th century. Americans tend to do what they like to do as individuals, without much need for social approval from groups or organized hierarchies.

On the other hand, people on the African continent are group-oriented and are more averse about accepting risks than are Americans. The history 
of colonialism in Africa shows us that those who took risks and fought for independence from their European rulers were punished most severely and this resulted in a collective tendency of Africans to avoid taking risks. The differences that African people exhibit compared with their European and American counterparts result in the development of work organizations and management systems which do not encourage risk-taking behaviors. This is especially important in the area of investments, important strategic endeavors, and the development of technology and innovations associated with the creation of new types of technologies.

The Berry et al. (2006) framework shows that these two types of adaptation result in the development of four types of processes and systems that are relevant for understanding the behaviors of humans in various social and organizational contexts. In addition, the various inferences that we make about how human beings are motivated in different parts of the world, and the extent to which they depict different levels of work ethic, are a direct function of these four processes. Work behaviors are a function of the ecological-, genetic-, cultural-, and acculturation-related influences depicted in Figure 1.1.

This framework is also found in the work of researchers in the field of culture and personality (e.g., Kardiner \& Linton, 1945; Whiting, 1974) as well as culture and management (e.g., Haire, Ghiselli, \& Porter, 1966; Kerr, Harbison, Dunlop, \& Myers, 1964). Berry et al. (2006) are careful to emphasize that this framework is a conceptual scheme and is not a theoretical model in the sense that it provides a general guide to the kinds of variables that we should be studying. The framework is based on the seminal work of Malinowski (1924) and Rivers (1901), who attempted to develop a scientific theory of culture in 1924. The views of these scholars are known as functionalism. They tend to explain the manner or the mechanism by which various elements within a system are related to each other and then how the system itself is related to the physical surroundings. For example, the reason people from sub-Saharan Africa are averse to taking risks can be explained by referring to their collective experience during their struggles against the colonial European countries.

In a related vein, the tendency for North Americans to be not so risk averse in their various social and organizational endeavors can be explained by the struggles of the early settlers (from 1607 to 1776) to adapt to a new continent when taking individual risks was rewarded. Therefore, the differential nature of independence as a central construct in the study of cultures can be traced to the differential experiences of humans in dissimilar social, historical, and political contexts. However, while we focus on the rewards provided by different environments we should not forget the role of ecological and physical demands on human behavior. One has 
to be highly concerned with work-related activities, not only in order to survive but also to prosper, in the harsh climates of northern states of the US. In contrast, the warmer climates of Central America make it difficult for people to work for sustained periods of time, which results in a collective de-emphasis of the value of work.

\section{CULTURE: DEFINITION AND RELATED ISSUES}

In the social sciences, it is imperative that we provide a robust definition of a concept. In the physical sciences, this is not typically the case. The concepts of mass, temperature, time, and light, which are essential concepts of physics, do not need elaborate definitions. However, the concept of culture is complex, dynamic, and fluid (Chiu \& Hong, 2006). No single definition of culture can fully capture the complexity of the concept. In fact, it is a construct that is useful not only for scholars in cross-cultural management but has provided also significant explanatory perspectives in anthropology, psychology, sociology, and these days even in the discipline of economics and finance.

The anthropologist Kluckhohn (1954) stated that culture is to society as memory is to humans. Triandis (1989) elaborates this suggestion: culture is what works in a particular ecology, so that it is important for humans to transmit it to the next generation. Human beings cannot function without relying on memory. Those with Alzheimer's disease (such as President Ronald Reagan a few years before his death in 2004) need continuous care from an attendant in order to perform the daily activities which most of us take for granted. A culture without memory would be equally dysfunctional. No society can function without shared norms and knowledge of its physical, historical, social, political, and economic environments.

If a group of people in a society has a drastically different understanding of its history compared with another group in the same society, then that society cannot function in a harmonious way. For example, if a significant portion of the US population strongly believed in 1776 that British colonial rule was desirable while another group believed the opposite, then the US would not be able to function as a harmonious society. In fact, in the late 18th century those with the first point of view generally moved to Canada. For another example, differences in views of slavery resulted in the devastating US Civil War that killed about 600,000 people. In short, it is imperative for the members of a society to have similar perspectives on the significance and functioning of important institutions and practices of the society.

Here is another example, this time from the field of management. 
Leadership, in the sense of focusing on getting things done, is highly valued in the US, the UK, France, Canada, and so on. On the other hand, in countries such as Japan, South Korea, India, and China, managers are regarded as most effective when they are nurturing, help their subordinates, and care about their well-being, even if their productivity is not as high and the contributions to the performance of the work group or the organization are in question. For example, in some cultures good managers find a spouse for employees needing one, which would be very unlikely in Western cultures.

There are numerous definitions of "culture." We provide a range of definitions to give the reader a sense of the meaning of this concept.

The anthropologist Redfield (1962) defined culture as "shared understandings made manifest in act and artifact." In short, culture is shared behavior and shared human-made aspects of the society. Thus, it includes "practices" (the way things are done here) and "values" (the way things should be done).

These older definitions of culture focus on what is outside the person (e.g., do people drive on the right or left?). The more recent definitions also stress what is inside the person (e.g., is the self independent or interdependent of in-groups?). Almost every aspect of psychological functioning is influenced, to some extent, by culture. Thus, it is best to view culture and psychology as complementing each other to make appropriate social behavior possible (Nisbett, Peng, Choi, \& Norenzayan, 2001; Shweder, 1991).

Triandis (1972 and in later years) emphasizes the subjective elements (the shared way concepts are defined, attitudes, beliefs, norms, values) of a society as being the important ingredients of its culture. Systems of beliefs (how things are linked in one's physical and social environment), norms (what is the right way to behave in a given social situation), attitudes (how to feel and react to an object, event, or person in accordance with one's beliefs and norms), behavioral intentions (expressed desire to perform certain acts in a social and organizational context), and values (preferred states of being in one's physical and social context) are included in the definition of culture according to Triandis (1972). The subjective culture of a nation or society is different from its objective culture (tools, roads, bridges), which is concerned with the structure of the physical surroundings. It is obvious that the objective culture of the state of Alaska in North America is quite different from the state of Guadalajara in Mexico. These two regions of the world are located in very dissimilar physical environments and are subject to different kinds of variations from the rays of the sun (resulting in very cold, temperate, or hot climates). Triandis observes that while objective cultures (just like in the eco-cultural framework we 
discussed above) are important for the evolution of subjective cultures, it is this latter type of culture which is most important in the prediction of social behavior. Subjective culture influences the conduct of human affairs and especially the conduct and functioning of work organizations and management processes.

This does not mean that material culture is unimportant. When an American comes across a man wearing an Arabic headdress or a turban, he or she may think that this person has a culture very different from his or her culture. Countries in different parts of the world have distinctive architectural preferences and even the curves associated with the roads are different. Most buildings in Cairo and Moscow are quite different from buildings in New York City or Vienna. However, such differences in the objective- or physical environment-related features of the countries are not especially important in the development of cultural norms and preferences of the people in these countries. While there might be a little importance attached to historically significant buildings and monuments (such as the Pyramids in Egypt, the Acropolis in Greece, the Taj Mahal in India, the Sears Tower in Chicago, and the Parliament Building in London), the point is that the subjective culture of a country evolves primarily based on the continuous interaction between the various facets of the eco-cultural model as suggested by Berry et al. (2006).

The next definition of culture that has had an impact on the conceptual foundations and empirical research in the management field is that advanced by Geert Hofstede (1980, 1983, 1991, 1995, 2001). He defines the culture of a society as the collective mental programming of a group of people in a given nation or geographic locale who speak the same language and have had considerable history in common.

Adopting this definition would immediately suggest that even though the Arabian Peninsula has numerous countries, the cultural milieu in which they find themselves is the same. The Arab culture is to be found in the Middle East and in North Africa, even though there are considerable differences in the political philosophies and economic values of these countries. However, consider the case of Turkey-a country located between the continents of Europe and Asia does not necessarily share the Arabic culture, and neither do Iran, Indonesia, or Malaysia for that matter. The countries of the Middle East and parts of northern Africa (i.e., Saudi Arabia, Iraq, Oman, UAE, Syria, Jordan, Lebanon, Egypt, Libya) share a strong religious orientation founded on Islamic principles. However, the degree of religiosity differs from country to country, with Saudi Arabia being strongly Islamic, having strong foundations in the Wahabian principles of Islam, and the UAE and Jordan being more relaxed in terms of strict adherence to Islamic values and practices. In 
Saudi Arabia in particular, a substantial percentage of women are not allowed to work outside their homes, which results in extremely low levels of participation of women in the workforce. Given the current foundations of the economy on petrochemical industries, the economic growth rate of Saudi Arabia is not affected by the lack of participation of women in the workforce. However, as the country slowly adapts to globalization and oil industries begin to lose their prominence in the global economy, this country is likely to experience a strong economic shock and perhaps a sharp decline in its standards of living.

Contrast this with the Islamic countries of Turkey, Indonesia, and Malaysia, where women work outside the home in large numbers and these countries do not share the philosophies of Islam that evolved in the dry, desert climates of the Arabian Peninsula. Recent reports show that growth rates of nations which have low rates of participation of women in the labor force are typically around 2 percent (Zakaria, 2011). Examples like this abound. The point is that the cultural underpinnings of a nation have profound implications for many aspects of economic, social, political, and organizational life. This is not to say that modern cultures of the West are necessarily superior to those of the East and of sub-Saharan Africa, central Asia, and Latin America. In a later section we will discuss the possible impact of ethnocentric thinking on the quality of scientific findings in the field of cross-cultural and international management research.

Students tend to confuse the concept of culture with the performing arts or refinements that are found within a nation. While the basic foundations of the societal culture can affect the evolution and quality of performing arts, let us be clear about the distinction between the concept of subjective culture and the notions of culture and cultural refinements as discussed in the realm of performing arts. The evolution of the Western classical music tradition has been largely possible due to the organized nature of activities that were possible in Europe, especially in Austria, Germany, and Italy. The greatest composers of the Western classical tradition were born and learned their trade in Central and South Central parts of Europe. Compare the structure of Western classical music with the musical traditions found in China, Japan, India, and the Arabian Peninsula. The number of musicians involved is quite different, and in Asia a great significance is given to musical instruments like the sitar, which are played by individual musicians and not necessarily in an orchestra, which is more common in Western classical music. A final analysis of the musical traditions of the world will reveal that they deal with the complexities of human emotions as well as destinies of humans expressed in the form of love, hate, anger, revenge, and peace. The forms of musical expression in the East are 
quite different from those in the West, but the essential purpose of music, drama, and other forms of the performing arts is to present the mosaic of human emotions in the cultural context of the countries.

Studies involving the construct of culture reject the idea of high culture or culture as artistic refinement of a group of individuals who speak the same language, live in the same geographical region of the world, and share a common history.

Culture should be distinguished from genetic influences on the one hand and personality on the other. A large part of human nature is a function of genetic heritage and upbringing: observable parts of human nature are relatively easily investigated but not the inferred characteristics. Personality characteristics reflecting aggressiveness versus submissiveness, activity versus passivity, introvertedness versus extrovertedness, and so on are not easily assessed in individuals, no matter what their national or cultural origins are. However, observable characteristics of human interactions and behaviors are studied by social psychologists, political scientists (the role of political and legal institutions and organizations), sociologists (studies of families, the role of authority relationships, significance of social movements, etc.), and economists (the growth and flow of money across national borders, growth rates of nations, entrepreneurial orientation, etc.).

The study of culture and cultural values is cultivated differently in different nations of the world. There has been a great deal of interest in understanding the underpinnings of national character (Kelman, 1968) of people in different countries. In fact, all over the world people have stereotypes about the attributes of peoples from other cultures. However, while these stereotypes have a "grain of truth," they are largely invalid. There is some truth in the notion that the Japanese tend to be more polite than Westerners; the British tend to be reserved and display very little emotion even during times of stressful interactions; and the Brazilians are fun-loving. However, when you meet a Japanese or British national, you may not necessarily find these qualities present in the specific person with whom you interact. Behavior is very strongly influenced by the situation. National character reflects the modal tendency of a group of people who have an identical language and have spent a significant amount of time with each other during a historical epoch. Triandis (1994) observed that the cultural values of the people living near the central square in Barcelona, Spain, which has been historically known to reflect some of the central characteristics of the Spanish, have remained more or less unchanged for several centuries. The central square has been a physical setting of considerable symbolic importance in Spanish history and has not been subjected to architectural innovations as has been the case in 
other parts of Barcelona. Families and businesses tend to interact in the same fashion as their ancestors did several centuries ago and the cultural characteristics are preserved. In contrast, modern urban centers in the US, Western Europe, and other advanced G-8 economies have undergone structural changes since World War II. The structure of inner cities in the US keeps changing (see Florida, 2008), resulting in continuous shifts in the evolution of the cultural patterns in these cities. Scholars conceptualize national characters to be enduring; however, we note that they are more enduring in traditional societies where scientific and technological changes have not affected the physical environment.

An earlier tradition that has influenced current research approaches in cross-cultural management is based on the social anthropologist perspective, which was largely derived from intensive, qualitatively designed fieldwork from different parts of the world. The American anthropologist Ruth Benedict (1946) was an important contributor to this perspective. She asserted that the national characters of various nations tend to be based on different historical, political, and cultural factors and also tend to be relatively resistant to change. Following this perspective, she noted that the national character of Japan was based on shame, whereas in the US, it was based on guilt (Benedict, 1946). She acknowledged that some individuals in either society might not fit the overall pattern, but believed the goals of the cultural anthropologist should be directed at understanding the overall cultural profile of a given nation or society. Her famous work, entitled The Chrysanthemum and the Sword (1946), was considered a classic and continues to be important even today in helping investigators discern some of the persistent patterns of Japanese character. Anthropologists like Ruth Benedict and Malinowski (1924) were strongly encouraged by psychoanalytic theories. The development of the massive Human Relations Area Files (HRAF), at Yale University in 1949, which includes paragraphs of the world's ethnographies, organized by topic, made it possible to test hypotheses linking different styles of child-rearing with some of the predominant practices of societies.

This culture and personality school of anthropology was useful in developing insights into nations that were small and quite homogeneous. Compared with this perspective, the psychometric perspective espoused by cross-cultural psychologists (e.g., Triandis, 1972; Berry, Poortinga, Segall, \& Dasen, 2006) emphasizes the notion that some psychological processes are of universal significance and utility because of their functional significance. These processes are termed etic processes and reflect the psychic unity of mankind. For example, in all cultures the idea of reciprocity (if you do something nice to me I will do something nice to you, but also if you hurt me I will hurt you) can be found. In contrast, there 
are nation-specific processes. These processes are called emic and connote the notion that while a large portion of the human experience in dissimilar geographical locales can be understood and interpreted using similar kinds of analytical lenses, there are other processes that are of unique significance in the socio-historical context of that society. The natives of the Tierra del Fuego in the southern tip of South America have a word (mimihlapinatapei) that means "looking at each other hoping that either one will offer to do something that both desire but are unwilling to be the first to do" (Triandis, 1994, p. 67). Clearly that concept is an emic; it does not occur in other cultures. The Maori people of New Zealand have some special practices that they initiate while confirming the passage to puberty for both boys and girls. These practices are not present in the Anglo-Saxon Protestant population of the Euro-centric New Zealanders.

In the next section we describe the broad goals of cross-cultural management. We will also be concerned with the relevance of the goals for helping us understand the process of globalization as it unfolds in different forms in different cultures.

\section{GOALS OF CROSS-CULTURAL MANAGEMENT}

The goals and objectives of cross-cultural management are discussed below.

1. It is important for students of human behavior as well as managers of multinational and global corporations to understand the nature of the specific mechanisms underlying the influence of cultural variations on people who work in organizations - whether they are for-profit or non-profit. It is also imperative that we get a better appreciation of the influences of cultural variations on organizational structures (Lincoln, Hanada, \& McBride, 1986). For example, why is it that Japanese multinational and global companies such as Toyota, Honda, Hitachi, Canon, and Fitzhugh tend to be much larger in terms of the number of individuals employed compared with US-based organizations in the same industries and pursuing similar strategies for increasing market share in the global economy? Increased understanding of the role of culture and cultural variations will be of significant value for designing large organizations in different societies, and also for enhancing their effectiveness.

2. As we have noted already, culture affects both observable and not so clearly observable states of humans in all parts of the world. If we gain increased understanding of the role of cultural variations in 
phenomena such as motivation to work, the significance of working and work ethic (MOW International Research Team, 1987), leadership effectiveness, and the ability of people to absorb increased volumes of information and knowledge, we will be in a better position to improve work effectiveness in different societies of the world. In other words, if we gain better insights in terms of how cultural factors selectively influence the process of energizing individuals to perform on the job and sustain their motivation over time, we will be a step closer to designing a global workforce that will be better equipped to deal with the turbulent character of global work environments in today's uncertain economy.

3. An understanding of the role of national character in the functioning of organizations in dissimilar cultural contexts of the world. For example, is the effectiveness of Japanese organizations a clear reflection of the fact that the Japanese national character is highly concerned with respect for social hierarchy and authority and has a strong in-group orientation, fostering loyalty and commitment to members of one's in-group? In a related vein, why is it that work organizations in sub-Saharan Africa, the Middle East, and Central America are not particularly effective in their ability and willingness to absorb technological innovations to sustain organizational growth and development (Steers, Nardon, \& Sanchez-Runde, 2010)? The fact that there are variations within countries due to differences in cultures of industries and corporate cultures is well known. Some industries, for instance, are more hierarchical than others. What is not yet developed is a body of practical insights in terms of utilizing these patterns of scientific knowledge in developing innovative techniques that are especially suitable in enhancing organizational growth, individual and group effectiveness, and satisfaction, as well as principle-oriented leadership. The gap from scientific insights that have developed in the field of cross-cultural psychology and cross-cultural management has not often been successfully filled. Advanced knowledge in the various topics covered in this book should be helpful in making organizations of the world and the people who work in them more effective as well as happy with their work lives.

4. Cultural variations can also tell us about the processes of organizational innovation and change. Anglo-Saxon Protestant cultures in nations such as the US, the UK, the Netherlands, the Scandinavian countries, and Australia have been successful in initiating various phases of industrial and information-based renaissance. Despite the fact that 20 percent of the world's population is Islamic and inhabits most of the Middle East and northern parts of Africa, this cultural 
region has not witnessed much technological innovation in recent years. This contrasts with the Islam of the 12th century, when Arabic was the language of science, when new techniques in medicine, algebra, and the work of the ancient Greek philosophers were transmitted by Arabs to medieval Europe. The closing of the Arab mind occurred when the Ottomans, in the 15th century, came from central Asia, and became the dominant culture in Islam. They were more interested in conquest than in science. Allawi (2009) is a Moslem who laments these developments. On the other hand, organizations in Scandinavian countries (characterized by low levels of population densities) and Israel (despite having to contend with hostile neighbors) have been springboards for important scientific and technological innovations in healthcare and other industries.

5. Globalization of businesses is creating a movement of both educated and not so educated workers from developing and poorer countries of the world to countries of the European Union, US, Canada, Australia, New Zealand, and the Middle East. The pattern of movement of these workers is discussed in the field of social demography. In fact, recent demographic trends show that Japan is experiencing a significant decline in the number of workers in the most productive years of their lives. The policy of immigration in Japan is restrictive and very different from that of Western countries, especially Canada, Australia, and New Zealand, where the influx of immigrants is key to sustaining economic activities on an ongoing basis. New Zealand, for example, has a population of about 3 million, and this population is primarily Euro-centric and has favored a relaxed lifestyle which is not necessarily conducive to major technological breakthroughs. New Zealand is pursuing an active immigration policy which encourages professionals from Asia (e.g., India, Indonesia, Singapore) to migrate permanently to this land, which has been known as a country "down under." The cross-cultural issues in the assimilation and functioning of these immigrant workers, whether they are educated or not, are vitally important for the government of New Zealand.

In a similar vein, Canada has a policy of immigration whereby immigrants are encouraged to retain their ethnic cultures and actively pursue entrepreneurial and professional activities which are typically enshrined in those cultures. In this aspect, the US, which has absorbed the largest number of immigrants during the past 150 years, is somewhat different. The policy in the US is one of assimilation, that is, encouraging immigrants to absorb the norms and values of the mainstream culture (i.e., Euro-centric) and not necessarily be highly vigilant in retaining the unique values of their ethnic cultures. In fact, 
the US is known as a country of immigrants and Silicon Valley in California has a workforce that is 25 percent foreign-born. A large number of high-tech professionals in Silicon Valley and parts of the northwestern US are from culturally dissimilar countries (i.e., dissimilar from the US), such as China, India, South Korea, Indonesia, Spain, and Mexico. Global corporations in these industries have realized the important need to encourage the valuing of cultural diversity in their organizational cultures. There have been many scientific research and training programs in the area of sustaining cultural diversity in order to enhance international competitiveness. Global consumer companies, for example Procter \& Gamble and Vicks International, organize international weeks in which members of various cultural groups display the significant objective and subjective artifacts of their culture. The idea is that members of ethnic groups tend to exhibit more organizational citizenship (e.g., help other workers even if that is not required by their job description) when they take pride in their ethnic heritage.

Knowledge of the dominant values of the various ethnic groups which actively seek immigration in advanced global economies (e.g., the US, Canada, and the European Union) and the oil-rich gulf countries (e.g., Saudi Arabia, Oman, and UAE) will be important in maintaining harmonious workforces at various levels of organizations. In this work it is helpful for people to learn to see the social behavior of members of other ethnic groups the way the ethnic groups perceive it (Triandis, 1994, Chapter 10).

\section{SOME OBSERVATIONS ON THE PRECEDENCE OF METHOD}

The method of cross-cultural psychology as well as related areas of inquiry (i.e., cross-cultural management, the role of cultural variables in management of subsidiaries of global corporations, etc.) is quite explicit in that it involves empirical study of members of different cultural and ethnic groups who have had different historical, social, and psychological experiences in different parts of the world. Such differences lead to predictable as well as statistically significant differences in both observed and implicit dependent variables of interest (Brislin, Lonner, \& Thorndike, 1967).

Recent work has conceived of culture both as an independent variable and as a dependent variable (Shweder, 1991). Experimental work is now done by priming a bi-cultural population, with stimuli that come from one 
or another culture, and by checking their behavior after the priming. The findings indicate, for instance, that if one uses a collectivist prime the collectivist responses of the samples increase and if one uses an individualist prime the individualist responses increase. This way it is possible to make sure that culture is the cause of a behavior (Hong, 2009).

In cross-cultural research, culture has the status of an independent variable whose influence is to be determined. Were culture a truly independent variable (i.e., one which would permit random assignment of subjects to it), the problems of drawing causal inferences that culture causes group behavior would be no more difficult than for any other independent treatment variable in experimentally controlled research, either in the laboratory or in field settings.

It is obvious that cultural experiences that different groups of populations have in different geographical locales of the world cannot be controlled, and hence culture has the status of a quasi-experimental variable (Campbell \& Stanley, 1966). Reviews of cross-cultural organizational research (Bhagat \& McQuaid, 1982; Bhagat, Kedia, Crawford, \& Kaplan, 1990; Child, 1981) began to reveal that there was a strong move from merely documenting descriptive and ethnographic differences across cultures to understanding the ideology of cultural differences as causal agents in various organizational phenomena. Yet, the attempts to delineate the roles of cultural differences in organizational behavior were too narrow, focusing on bivariate comparisons of important organizational phenomena (e.g., comparing job satisfaction levels of US workers with those of Mexican workers; Slocum, Topichak, \& Kuhn, 1972). Current studies are more sophisticated, and there seems to be a considerable amount of emphasis on the cultural variation of individualism-collectivism (I-C) to explain numerous organizational phenomena across the cultural divide (Bond, 1997). Despite some conceptual and empirical confusion surrounding the $\mathrm{I}-\mathrm{C}$ construct (Oyserman, Coon, \& Kemmelmeir, 2002; Brewer \& Chen, 2006), this variation of cultural difference seems to arouse the interest of international organizational behavior scholars all over the world.

To be sure, this dimension is fundamental to understanding the nature of cultural variations that are found in different geographical locales of the six continents (Asia, Europe, North America, South America, Africa, and Oceania). However, there are other dimensions of cultural variations that are perhaps better suited for studying organizational phenomena such as complex decision-making processes, creativity, problem-solving tasks, and irrational approaches for solving organizational problems. In a sense, the field is ready to explore the theoretical foundations along with empirical research of other dimensions which might be less powerful - that 
is, predictive - in explaining certain kinds of dependent organizational phenomena. Such a focus will begin to shed light on unexplored territories relating to behavior in and around organizations.

Cultural differences are also a function of the strength of social norms and mores (Gelfand, Erez, \& Aycan, 2007), nature of roles (McAuley, Bond, \& Kashima, 2002; Smith, Bond, \& Kagitcibasi, 2006), and traditional beliefs regarding the nature of the physical and social environment in which one lives (Leung, Bond, de Carrasquel, Munoz, Hernandez, et al., 2002) and domain-specific implicit or explicit theories (Chiu, Hong, Morris, \& Menon, 2000). Sources of cultural differences might also lie outside the domain of consciousness, which means that unobtrusive approaches for assessing these influences may also be needed.

Level of analysis tends to confuse cross-cultural researchers. The individual-level bias in assessing cultural differences is strongly grounded at both the level of theory and measurement. Organizational research involving cultural differences continues to apply culture-level theories (such as Hofstede's framework) in predicting individual-level phenomena (such as the job satisfaction of managers in a high-tech organization). In future research investigations regarding cultural differences, it is crucial that issues concerned with the level of analysis be examined and applied with more precision. Detection of cultural differences at the individual, dyadic, team, work-group, and at the organizational level of analysis should be made by employing constructs that are appropriate for multilevel (i.e., meso) research. Both conjunctive and disjunctive formulations of influences from different levels of analysis need to be integrated in order to explain group-level and organizational-level phenomena.

\section{CONCLUDING REMARKS}

In the current era of globalization, opportunities for expanding business transactions across borders and nations have increased greatly. Gone are the years after World War II when the US was the dominant economy in the world, having over 380 multinational and global corporations within its territory. During the past decade, there has been significant growth in some of the economies which were regarded as not being particularly effective in absorbing the scientific and technological advances that typically accompany economic globalization. Some of these countries are also moving ahead of some of the Western economies (Zakaria, 2011). For example, China and India, and lately Brazil and Russia, are experiencing economic growth rates in the range of 8-9 percent (since 1978 in the case of China and 1991 for India). The BRIC economies are countries that do not 
reflect the cultural values of the dominant economies of the West (i.e., the US, UK, Canada, France, Germany, etc.). However, the citizens of these countries are just as interested in enjoying a global and affluent lifestyle as the citizens of the Western countries. In order for the organizational researcher to understand the role of cultural differences in the evolution of globalization as well as global patterns or thoughts in the countries of Asia, Latin America, Southern Europe, and Africa, it is important to develop appropriate theoretical models using multilevel-based analyses. We hope this chapter has provided some of the primary impetus in understanding the significance of cultural differences that exist in differing nations of the world and their implications for creating a better, more affluent and just world tomorrow.

\section{REFERENCES}

Allawi, A.A. (2009). The crisis of Islamic civilization. New Haven, CT: Yale University Press.

Benedict, R. (1946). The chrysanthemum and the sword. Boston, MA: Houghton Mifflin.

Berry, J.W., Poortinga, Y.H., Segall, M.H., \& Dasen, P.R. (2006). Cross-cultural psychology. Cambridge: Cambridge University Press.

Bhagat, R.S. \& McQuaid, S.J. (1982). The role of subjective culture in organizations: A review and direction for future research. Journal of Applied Psychology, 67(5), 653-85.

Bhagat, R.S., Kedia, B.L., Crawford, S.E., \& Kaplan, M.R. (1990). Crosscultural issues in organizational psychology: Emergent trends and discussion for research in the 1990s. In C.L. Cooper \& I.T. Robertson (Eds). International review of industrial and organizational psychology (pp.59-99). New York: John Wiley.

Bond, M.H. (1997). Adding value to the cross-cultural study of organizational behavior. In M.H. Bond, C.P. Earley, \& M. Erez (Eds). New perspectives on international industrial/organizational psychology (pp.256-75). San Francisco: The New Lexington Press/Jossey-Bass.

Brewer, M.B. \& Chen, Y.R. (2006). Where (who) are collectives in collectivism? Toward conceptual clarification of individualism and collectivism. Psychological Review, 114(1), 133-51.

Brislin, R.W., Lonner, W.J., \& Thorndike, R.M. (1967). Cross-cultural research methods. New York: John Wiley.

Campbell, D.T. \& Stanley, J. (1966). Experimental and quasi-experimental design for research. Chicago: Rand-McNally.

Child, J. (1981). Culture, contingency and capitalism in the cross-national study of organizations. Research in Organizational Behavior, 2, 303-56.

Chiu, C. \& Hong, Y. (2006). The social psychology of culture. Principles of Social Psychology Series. New York: Psychology Press.

Chiu, C., Hong, Y., Morris, M.W., \& Menon, T. (2000). Motivated cultural cognition: The impact of implicit cultural theories on dispositional attribution varies 
as a function of need for closure. Journal of Personality and Social Psychology, 78, 247-59.

Florida, R. (2008). Flight of the creative class. New York: Harper Business.

Gelfand, M.J., Erez, M., \& Aycan, Z. (2007). Cross-cultural organizational behavior. Annual Review of Psychology, 58, 479-514.

Goldman Sachs (2003). Dreaming with the BRICS: The path to 2050. http://www2. goldmsachs.com/ideas/brics-dream-html.

Haire, M., Ghiselli, E.E., \& Porter, L.W. (1966). Managerial thinking: An international study. New York: John Wiley \& Sons.

Hofstede, G. (1980). Culture's consequences: International differences in work related values. Beverly Hills, CA: Sage.

Hofstede, G. (1983). The cultural relativity of organizational practices and theories. Journal of International Business Studies, 14, 75-89.

Hofstede, G. (1991). Cultures and organizations: Software of the mind. London: McGraw-Hill.

Hofstede, G. (1995). Multilevel research of human systems: Flowers, bouquets, and gardens. Human Systems Management,14, 207-17.

Hofstede, G. (2001). Culture's consequences (2nd edn). Thousand Oaks, CA: Sage.

Hong, Y.-Y. (2009). A dynamic constructivist approach to culture: Moving from describing culture to explaining culture. In R.S. Wyer, C. Chiu, \& Y. Hong (Eds). Understanding culture: Theory, research and application (pp.3-24). New York: Psychology Press.

Kardiner, A. \& Linton, R. (1945). The individual and his society. New York: Columbia University Press.

Kelman, H.C. (1968). International relations: Psychological aspects. In D.L. Sills (Ed.). International encyclopedia of the social sciences (Vol. 8, pp. 75-83). New York: Macmillan and Free Press.

Kerr, C., Harbison, C.A., Dunlop, J.T., \& Myers, A. (1964). Labor and management in industrial society. New York: Oxford University Press.

Kluckhohn, C. (1954). Southwestern studies of culture and personality. American Anthropologist, 56(4), 685-97.

Leung, K., Bond, M.H., Reimel De Carrasquel, S., Hernandez, M. et al. (2002). Social axioms: The search for universal dimensions of general beliefs about how the world functions. Journal of Cross-Cultural Psychology, 33(3), 286-302.

Lincoln, J.R., Hanada, M., \& McBride, K. (1986). Organizational structures in Japan and U.S. manufacturing. Administrative Science Quarterly, 31, 338-64.

Malinowski, B. (1924). Special foreword. In W.H.R. Rivers, Social organization. London: Kegan Paul, Trench, Trubner.

McAuley, P.C., Bond, M.D., \& Kashima, E. (2002). Toward defining situations objectively: A culture-level analysis of role dyads in Hong Kong and Australia. Journal of Cross-Cultural Psychology, 33, 363-79.

McClelland, D. (1961). The achieving society. Princeton, NJ: Van Nostrand.

MOW International Research Team (1987). The meaning of work: An international perspective. London: Academic Press.

Myrdal, G. (1968). The Asian drama. New York: Pantheon.

Nisbett, R.W., Peng, K., Choi, I., \& Norenzayan, A. (2001). Culture and systems of thought: Holistic versus analytic cognition. Psychological Review, 108(2), 291-310. 
Oyserman, D., Coon, H.M., \& Kemmelmeier, M. (2002). Rethinking individualism and collectivism: Evaluation of theoretical assumptions and meta-analysis. Psychological Bulletin, 128, 3-72.

Redfield, M.P. (1962). Human nature and the study of society. The papers of Robert Redfield. Chicago: University of Chicago Press.

Rivers, W.H.R. (1901). 'Vision'. In Physiology and psychology. Part I: Reports of the Cambridge anthropological expedition to Torres Straits (vol. II, pp. 44-58). Cambridge: Cambridge University Press.

Shweder, R.A. (1991). Thinking through cultures: Expeditions in cultural psychology. Cambridge, MA: Harvard University Press.

Slocum, J.W., Topichak, P.M., \& Kuhn, D. (1972). Do cultural differences affect job satisfaction? Journal of Applied Psychology, 56, 177-8.

Smith, P.B., Bond, M.H., \& Kagitcibasi, C. (2006). Understanding social psychology across cultures: Living and working in a changing world. London: Sage.

Steers, R., Nardon, L., \& Sanchez-Runde, C. (2010). Managing across cultures: Challenges and strategies. Cambridge: Cambridge University Press.

Tanaka-Matsumi, J. \& Draguns, J.G. (1987). Culture and psychopathology. In J.W. Berry, M.H. Segall, \& C. Kagitcibasi (Eds). Handbook of cross-cultural psychology (pp. 449-92). Boston: Allyn \& Bacon.

The Economist (2010). Country report on South Africa and new political strategies in Japan. 5 June.

Triandis, H.C. (1972). The analysis of subjective culture. New York: Wiley.

Triandis, H.C. (1989). The self and social behavior in differing cultural context. Psychological Review, 96, 506-20.

Triandis, H.C. (1994). Culture and social behavior. New York: McGraw-Hill.

Whiting, J.W.M. (1974). A model for psychocultural research. Annual report. Washington, DC: American Anthropological Association.

Zakaria, S. (2011). The post-American world 2.0. New York: W.W. Norton. 